Research Article

\title{
Synthesis of Pectiniform Polyurethane-Modified Polycarboxylate and Its Preliminary Application in Ultrahigh-Performance Concrete
}

\author{
Shuncheng Xiang $(\mathbb{D}$ and Yingli Gao \\ Key Laboratory of Special Environment Road Engineering of Hunan Province, Changsha University of Science \& Technology, \\ Changsha 410114, Hunan, China \\ Correspondence should be addressed to Yingli Gao; yingligao@126.com
}

Received 29 April 2020; Revised 4 June 2020; Accepted 21 August 2020; Published 8 September 2020

Academic Editor: Xue Luo

Copyright ( $) 2020$ Shuncheng Xiang and Yingli Gao. This is an open access article distributed under the Creative Commons Attribution License, which permits unrestricted use, distribution, and reproduction in any medium, provided the original work is properly cited.

In this paper, modified polyurethane prepolymer was synthesized by the segmental synthesis method using isophorone diisocyanate (IPDI), hydroxyl-terminated silicone, and polyether glycol dimethylolpropionic acid as raw materials. After that, pectiniform polycarboxylate, of which side chains were in roughly the same polymerization degree and main chains were in different lengths, was synthesized at normal temperature in the complex initiation system of $\mathrm{H}_{2} \mathrm{O}_{2}$, APS, sodium bisulfite, and Vc. Then, compared with commercial Sika polycarboxylate, their applications in ultrahigh-performance concrete (HUPC), including flowability, strength, drying shrinkage, and autogenous shrinkage, were investigated. The results showed that, due to the molecular structure of polyorganosiloxane, the synthesized polycarboxylate could be better dispersed. Dosage of silica fume could effectively improve the compressive strength of UHPC, while slag had a certain negative impact on its strength. Incorporation of slag and silica fume could effectively reduce the dry shrinkage of UHPC.

\section{Introduction}

In recent years, polycarboxylate (PCE) had developed rapidly. By changing the chemical structure of main chain, branch chain, and carboxylic acid group in polycarboxylate molecules, polycarboxylate became capable of protecting the collapse, controlling condensation, and reducing shrinkage. Studies on the chemical structure changes of polycarboxylate mainly focus on the charge density differentiation, branch chain length, main chain length, and the functional groups contained [1]. It had been found that these groups were adsorbed on the surfaces of silicate cement hydration products and cement particles, which not only led to the formation of adsorption layer but also destroyed the flocculation structure between silicate particles [2]. After the addition of polycarboxylate, the electrostatic repulsion and spatial steric resistance could greatly change the force between silicate cement particles and the physical-chemical properties of the solid-liquid interface, making the silicate cement particles evenly distributed, thus affecting the flowability and other properties of cement [3]. However, polycarboxylate was commonly synthesized by the heating synthesis method, in which synthesis temperature was required to be between $60^{\circ} \mathrm{C}$ and $90^{\circ} \mathrm{C}$ or even higher and the content of synthesized polycarboxylate was relatively low, resulting in increased synthesis and marketing costs. On this basis, synthesis of polycarboxylate at room temperature had become a trend of development.

In the past two decades, concrete admixture technology had been developed rapidly. The invention of polycarboxylate made it possible to prepare concrete mixtures with low water-binder ratio and high flowability. Moreover, some functions could be further enhanced by means of compounding. Therefore, the design and selection of an appropriate polycarboxylate could not only effectively reduce the water demand of UHPC and obtain the required 
workability but also promote its condensation and hardening and strength development of UHPC and, at the same time, obtain better other performance $[4,5]$. It had been proved that adding some active admixtures such as silica fume and ultrafine slag was an effective way to prepare highperformance concrete. Adding any one admixture could improve the performance of concrete, but there were still some shortcomings [6].

By controlling the molar ratio of acrylic acid and large monomer, polyurethane-modified polycarboxylate (MPCE) was synthesized at room temperature in this work, and its application in ultrahigh-performance concrete was studied by comparing Sika high-performance polycarboxylate.

\section{Experimental Details}

2.1. Materials. The raw materials used include P.I 42.5 cement, silica fume, slag, and fly ash, and the chemical compositions are shown in Table 1 . The average particle size of P.I 42.5 cement was $36.96 \mu \mathrm{m}$, the average particle size of slag was $20.30 \mu \mathrm{m}$, and the average particle size of silica fume was $0.22 \mu \mathrm{m}$. The commercially available Sika was a high-performance polycarboxylate, of which the molecular structure is shown in Figure 1. The synthetic materials used include isophorone diisocyanate (IPDI), 1-4-butanediol, dihydroxymethyl propionic acid (DMPA), N-methyl-2pyrrolidone, hydroxyl-terminated polysiloxane, polyether diol, and isoprene polyoxyethylene ether (TPEG) with a molecular weight of 2400, acrylic acid (AA), thioglycolic acid, sodium methallyl sulfonate (SMS), polyethylene glycol -200 (PEG-200), toluene sulphonic acid, hydrogen peroxide $\left(\mathrm{H}_{2} \mathrm{O}_{2}\right)$, ascorbic acid $(\mathrm{Vc})$, ammonium persulfate (APS), dilauryl dibutyltin, sodium hydroxide, and deionized water.

2.2. Synthesis of Side Chains. The synthesis equation and the designed side chain molecular structure are shown in Figure 2. In the process of synthesis, alcohols and amines containing hydroxyl groups or amino groups with low molecular weight and multifunctional groups were introduced into the main chain of polycarboxylate molecules to increase the number of short branched chains, making the long branched chains of polyethers and the short branched chains of alcohols and amines distributed alternately and thus increasing the dispersibility and adaptability of polycarboxylate. The specific operation was as follows.

Initially, $22.2 \mathrm{~g}$ of isophorone diisocyanate was weighed and transferred to a four-neck round-bottom flask at $60-80^{\circ} \mathrm{C}$, and $25 \mathrm{~g}$ of polyethylene glycol (Mw: 1000) was added to the polyethylene glycol along with a quantity of dibutyltin dilaurate. After $1 \mathrm{~h}, 3.35 \mathrm{~g}$ of solid DMPA was added and dissolved with $5-8 \mathrm{ml}$ of $\mathrm{N}$-methyl-2-pyrrolidone. For prepolymerization, a solution containing $9 \mathrm{~g}$ of hydroxyl-terminated polysiloxane, $3 \mathrm{~g}$ of 1,4-butanediol, and $2.5 \mathrm{~g}$ of sodium methallyl sulfonate (SMS) was added to the bottom flask. A polyurethane prepolymer was obtained when the concentration of free -NCO was reduced to $16 \%$.

The polymerization reaction of the polyurethane side chain was as follows:<smiles>[R7]OC(C)CC([R12])(C)CC(C)OCC(C)C</smiles><smiles>[R8]C(C)(C)[Si](C)(C)O[Si](C)(C)C</smiles>

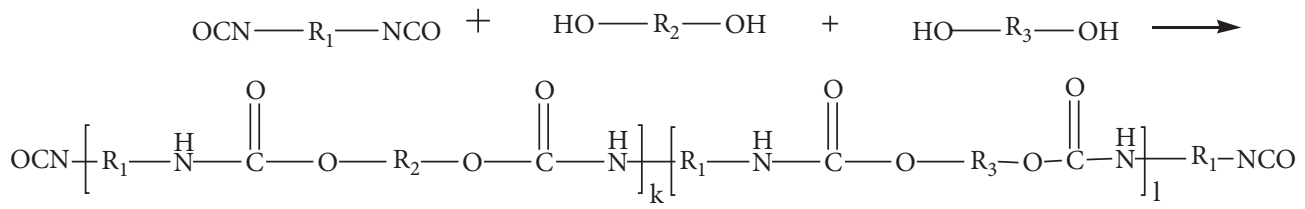

marked as $\mathrm{OCN}-\mathrm{R}_{4}-\mathrm{NCO}$ ) 
Table 1: Chemical composition of PI 42.5 Portland cement, slag, fly ash, and silica fume $w$ (\%).

\begin{tabular}{lccccc}
\hline \multirow{2}{*}{ Material } & \multicolumn{3}{c}{ Chemical composition $w(\%)$} & $\mathrm{CaO}$ & $\mathrm{MgO}$ \\
& $\mathrm{SiO}_{2}$ & $\mathrm{Al}_{2} \mathrm{O}_{3}$ & $\mathrm{Fe}_{2} \mathrm{O}_{3}$ & 64.67 & 2.68 \\
Cement & 25.26 & 6.38 & 4.05 & 0.45 & 0.83 \\
Silica fume & 90.82 & 1.03 & 1.50 & 39.11 & 10.04 \\
Slag & 33 & 13.91 & 0.82 & 5.53 & 1.34 \\
Fly ash & 54.29 & 22.55 & 2.56 \\
\hline
\end{tabular}
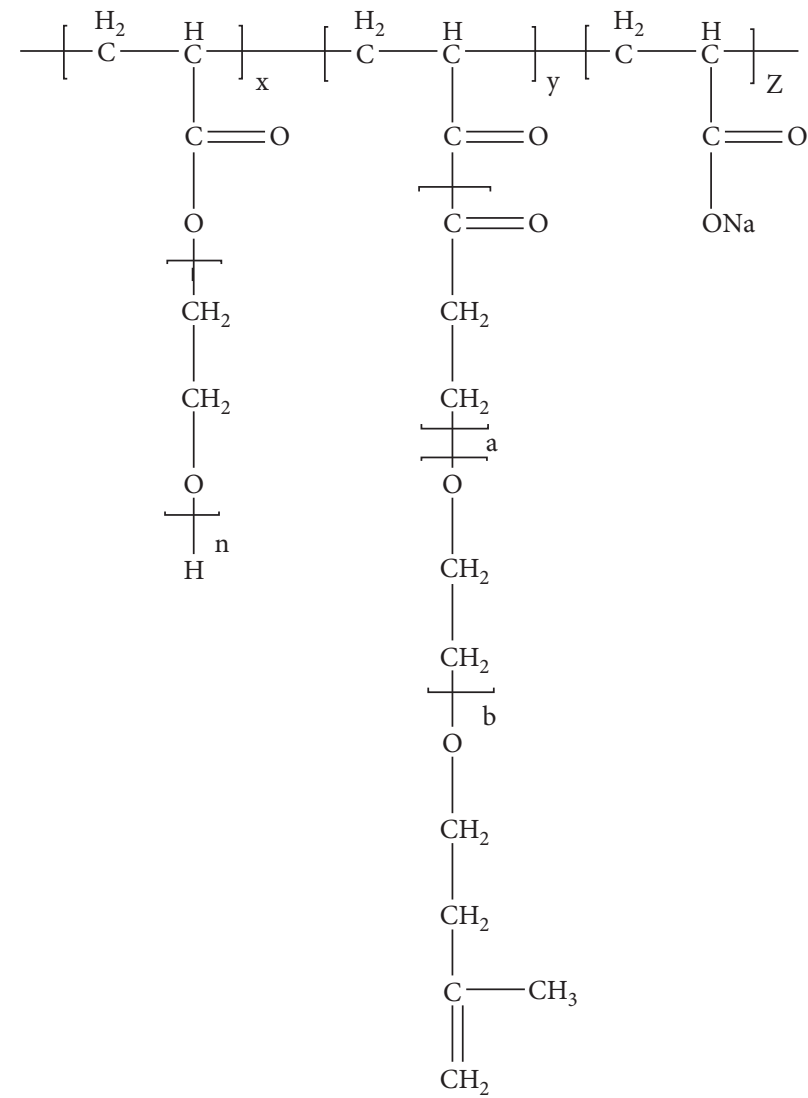

FIgURE 1: Chemical structure of commercial Sika polycarboxylate.

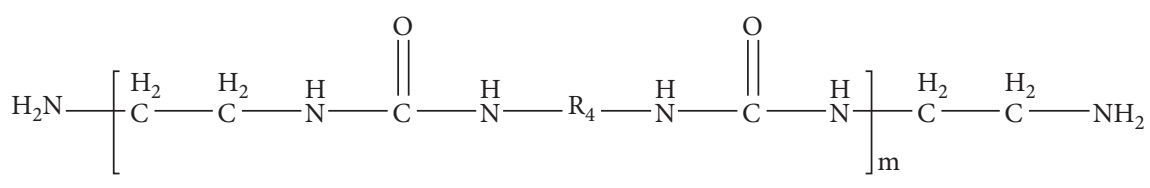

FIgURE 2: Side chain's reaction and its molecular structure.

The chain extending reaction was as follows:

$\mathrm{OCN}-\mathrm{R}_{4}-\mathrm{NCO}+\mathrm{H}_{2} \mathrm{~N}-\stackrel{\mathrm{H}}{\mathrm{C}}-\stackrel{\mathrm{H}_{2}}{-}-\mathrm{NH}_{2}$

2.3. Preparation of Modified PCE (M-PCE). In the synthesis, a solution containing $120 \mathrm{~g}$ of TPEG, $80 \mathrm{ml}$ of deionized water, and $10 \mathrm{~g}$ of PEG-200 was fully stirred in a $250 \mathrm{ml}$ four- neck round-bottom flask. Another solution containing $0.1 \mathrm{~g}$ of dibutyltin dilaurate, $1.2 \mathrm{~g}$ of toluene sulphonic acid, and $34 \mathrm{~g}$ of $30 \%$ hydrogen peroxide was added. In addition, 2 
groups of solutions (group A and group B) were prepared for the next step:

Group A: $10.8 \mathrm{~g}$ AA, $0.384 \mathrm{~g}$ thioglycolic acid, and $20 \mathrm{~g}$ deionized water.

Group B: $3.4 \mathrm{~g} \mathrm{Vc}, 0.6 \mathrm{~g}$ ammonium persulfate, and $20 \mathrm{~g}$ deionized water.

With using a peristaltic pump, the two groups of solutions were added dropwise into the flask at $2 \mathrm{ml} / \mathrm{min}$ within $1.5 \mathrm{~h}$. The solution was heated and incubated for $3 \mathrm{~h}$ at $40^{\circ} \mathrm{C}$ before adding $\mathrm{NaOH}$ to adjust the $\mathrm{pH}$ to 6-7 to prepare PCE solution. The chemical structure of M-PCE is shown in Figure 3.

2.4. Water-Reducing Rate Test of Cement Mortar. According to GB/T8077-2012 "Concrete Admixture Homogeneity Test Method," the mortar water-reducing rate of polycarboxylate was tested after jumping for 30 consecutive beats based on the following formula:

$$
\text { water }- \text { reducing rate }=\frac{M_{0}-M_{1}}{M_{0}} \times 100 \%,
$$

where $M_{0}$ represents the water consumption when the flowability of mortar was $180 \mathrm{~mm} \pm 5 \mathrm{~mm}$ and $M_{1}$ represents the water consumption when the flowability of admixture mortar reached $180 \mathrm{~mm} \pm 5 \mathrm{~mm}$.

2.5. Mix Rate of UHPC. Based on quadrature design, the content of polycarboxylate was $2 \%$ of the binder component (mass ratio), the water-binder ratio of ultrahigh strength concrete was 0.18 , and the sand-binder ratio was 1.0 . The mix ratio is shown in Table 2.

Quaternion orthogonal design was adopted in this work. Matlab software was used for calculation; if the mixture was composed of four components $X 1, X 2, X 3$, and $X 4$, then

$$
\begin{aligned}
Y= & \beta_{1} X 1+\beta_{2} X 2+\beta_{3} X 3+\beta_{4} X 4+\beta_{12} X 1 X 2 \\
& +\beta_{13} X 1 X 3+\beta_{14} X 1 X 4+\beta_{23} X 2 X 3+\beta_{24} X 2 X 4 \\
& +\beta_{34} X 3 X 4+\beta_{123} X 1 X 2 X 3+\beta_{124} X 1 X 2 X 4 \\
& +\beta_{134} X 1 X 3 X 4+\beta_{234} X 2 X 3 X 4+\beta_{1234} X 1 X 2 X 3 X 4,
\end{aligned}
$$

where $Y$ was the dependent variable, which could be any structure or performance characteristics of cement-based materials; $I$ was a coefficient; and $X 1, X 2, X 3$, and $X 4$ were four components. Fifteen orthogonal designs were used to design the compos7ition of cementitious materials, and then, the relation between the composition of cementitious materials and the performance of ultrahigh strength concrete was established.

2.6. Flowability. The sand with a particle size below $2.36 \mathrm{~mm}$ was selected, the cementation material mass was $200 \mathrm{~g}$, the sand-binder ratio was $1: 1$, the water-binder ratio was 0.18 , and the mixing amount of polycarboxylate mother liquor was $2 \%$. The mortar flowability was tested when it jumped 30 times on the table.

2.7. Strength. In the test of cement mortar, a group of $40 \mathrm{~mm} \times 40 \mathrm{~mm} \times 160 \mathrm{~mm}$ test bodies was formed by using fine sand with particle size below $2.36 \mathrm{~mm}$, with the sandbinder ratio of $1: 1$, and the flowability of cement mortar maintained above $140 \mathrm{~mm}$. The test mold was a triple mold, and the curing time was 24 hours; the temperature of the curing box with mold curing was kept at $20^{\circ} \mathrm{C} \pm 1^{\circ} \mathrm{C}$, and the relative humidity was not lower than $90 \%$. Then, the mold was removed and put into the steam curing chamber; the drying chamber temperature was $20^{\circ} \mathrm{C} \pm 3^{\circ} \mathrm{C}$. The strength of mortar at the 1 st day, $3 \mathrm{rd}$ day, 7 th day, 14 th day, and 28 th day was measured.

2.8. Dry Shrinkage. According to the provisions of JC/T6032004 "Dry Shrinkage Test Method of Cement Mortar," a set of $25 \mathrm{~mm} \times 25 \mathrm{~mm} \times 280 \mathrm{~mm}$ test bodies was prepared. After testing initial reading, the test body was put into the drying chamber, the drying chamber temperature was $20^{\circ} \mathrm{C} \pm 3^{\circ} \mathrm{C}$, the relative humidity was $50 \% \pm 4 \%$, and then the length of test body at the 1st day, 3rd day, 7th day, 14th day, 21th day, 28th day, 56th day, and 90th day was measured.

The results were calculated as follows:

$$
S_{n}=\frac{\left(L_{0}-L_{28}\right) \times 100}{280}
$$

where $S_{n}$ is the dry shrinkage rate of cement mortar test body at the $n$-th day, percentage (\%); $L_{0}$ is the initial reading, $\mathrm{mm}$; $L_{28}$ is the measured reading at the 28th day, mm; and 280 is the effective length, $\mathrm{mm}$.

2.9. Autogenous Shrinkage. The autogenous shrinkage of mortar in self-compacting cement mortar was measured by jointly using bellow and noncontact probe. The inner diameter of the bellow was $20 \mathrm{~mm}$, and the length range was $340 \pm 5 \mathrm{~mm}$, which could transform the volume deformation of the flowing mortar into the length deformation. The flowability of cement mortar was kept above $140 \mathrm{~mm}$, and the autogenous shrinkage change of cement mortar was continuously measured and recorded within 72 hours after casting.

\section{Results and Discussion}

3.1. Mortar Water-Reducing Rate. The water consumption of benchmark mortar without using polycarboxylate was $205.0 \mathrm{~g}$. After jumping 30 times, the flowability was $186 \mathrm{~mm}$ and $175 \mathrm{~m}$, with an average of about $180 \mathrm{~mm}$. The experimental results are shown in Table 3.

It could be seen from the above results that the water reduction rate of M-PCE in mortar was not much different from that of Sika. From the perspective of molecular structure, Sika's dispersion groups were mainly long-chain alkyl monomers, and its dispersion principle was mainly electrostatic repulsion and steric hindrance effect. In 


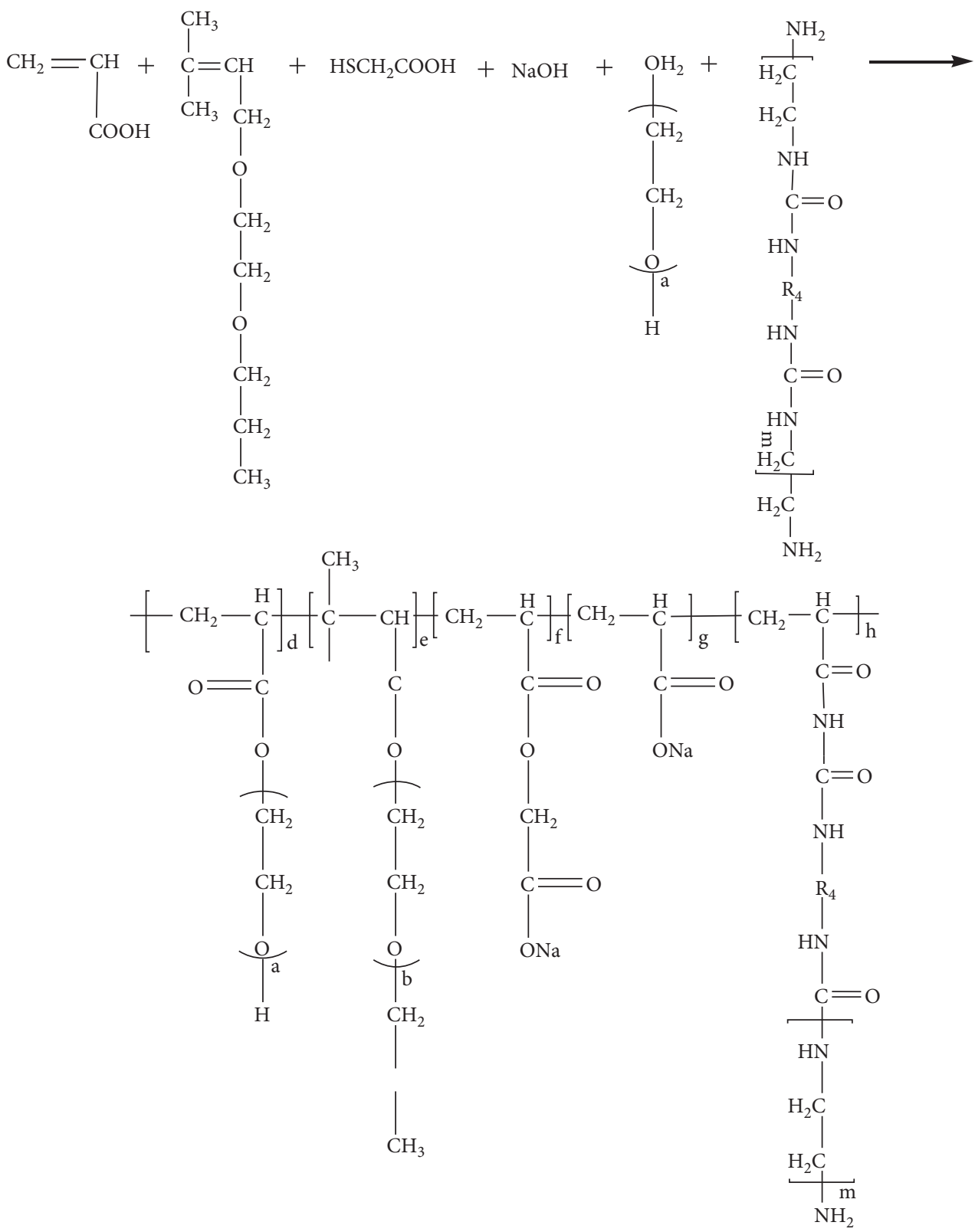

FIGURE 3: Chemical structure of synthesized M-PCE.

contrast, M-PCE's dispersion ability was promoted by the strong chemical bond caused by siloxane groups in M-PCE and silicate phase [7]. In addition, M-PCE had longer side chains than PCE, so it had better steric hindrance [8] and excellent dispersion in cement. Levi et al. [9] obtained a similar conclusion by testing the effect of three types of silane (triethoxy silane (TEOS), 3-aminopropyl triethoxy silane (APTES), and N-2-aminoethyl-3-aminopropyl trimethoxy silane (AEAPTMS)) on mobility. The results showed that AEAPTMS had the best dispersion in fresh cement paste. The main reason was that the siloxane group in the polyurethane side chain produced by alkoxy hydrolysis of silane molecules acted as an anchoring group on the cement surface, resulting in full adsorption of silane molecules on the cement particle, and siloxane chain in a certain way exerted the steric effect between the cement particles, resulting in the disperse effect of cement. The anchoring capacity of the siloxane group on cement or hydration products had been demonstrated by the enhanced adsorption behavior of the silane-modified polycarboxylate in cement [10].

3.2. Flowability. The flowability of UHPC with the cementitious system of cement-silica fume-slag-fly ash is shown in Table 4. The quaternion orthogonal analysis is shown in Figures 4 and 5.

According to the UHPC flowability test results in Table 4, the relationship between the initial flowability $Y$ of UHPC with M-PCE or Sika used as polycarboxylate and the composition of cementing material was established, as shown in the following equation: 
TABLE 2: Binder compositions of UHPC.

\begin{tabular}{lcccc}
\hline No. & Cement (\%) & Silica fume (\%) & Slag (\%) & Fly ash $(\%)$ \\
\hline N1 & 100 & 0 & 0 & 0 \\
N2 & 50 & 50 & 0 & 0 \\
N3 & 50 & 0 & 50 & 0 \\
N4 & 50 & 0 & 0 & 50 \\
N5 & 75 & 25 & 0 & 0 \\
N6 & 75 & 0 & 25 & 0 \\
N7 & 75 & 0 & 0 & 25 \\
N8 & 50 & 25 & 25 & 0 \\
N9 & 50 & 25 & 0 & 25 \\
N10 & 50 & 0 & 25 & 25 \\
N11 & 66.6 & 16.7 & 16.7 & 0 \\
N12 & 66.6 & 16.7 & 0 & 16.7 \\
N13 & 66.6 & 0 & 16.7 & 16.7 \\
N14 & 50 & 16.7 & 16.7 & 16.7 \\
N15 & 62.5 & 12.5 & 12.5 & 12.5 \\
\hline
\end{tabular}

$$
\begin{aligned}
Y_{(\mathrm{M}-\mathrm{PCE})}= & 1.7 X 1+0.5 X 2+1.3 X 3+5.6 X 4+0.018 X 1 X 2 \\
& +0.043 X 1 X 3+0.113 X 1 X 4+0.341 X 2 X 3 \\
& +1.009 X 2 X 4+0.56 X 3 X 4-0.00509 X 1 X 2 X 3 \\
& -0.01644 X 1 X 2 X 4-0.00909 X 1 X 3 X 4 \\
& -0.06326 X 2 X 3 X 4-0.0014717 X 1 X 2 X 3 X 4,
\end{aligned}
$$

$$
\begin{aligned}
Y_{(\text {Sika) }} & =1.7 X 1+1.9 X 2+2.18 X 3+4.37 X 4+0.064 X 1 X 2 \\
& +0.0624 X 1 X 3+0.0878 X 1 X 4+0.9581 X 2 X 3 \\
& +1.1522 X 2 X 4+0.6354 X 3 X 4-0.017113 X 1 X 2 X 3 \\
& -0.19207 X 1 X 2 X 4-0.011209 X 1 X 3 X 4 \\
& -0.023754 X 2 X 3 X 4-0.0019255 X 1 X 2 X 3 X 4 .
\end{aligned}
$$

According to formulas (4)-(5), the influence of silicate cement on the flowability of UHPC with M-PCE or Sika was the same. The values of $\beta_{123}, \beta_{124}, \beta_{134}, \beta_{234}$, and $\beta_{1234}$ were all negative, indicating that the use of three or more cementitious materials had a negative synergistic effect on the flowability of UHPC although this effect was very weak. On the contrary, the remaining parameters were all positive, indicating that the use of one or two cementitious materials alone had some positive effect on the flowability of UHPC.

As could be seen from Table 4, the flowability of UHPC decreased as the amount of silica fume increased from 0 to $50 \%$. This was due to that the silica fume had a small particle size and the surface of silica fume would absorb a lot of water reducers [11]. Under the action of polycarboxylates, silica fume acted as an ultrafine particle to disperse cement particles, releasing more free water $[12,13]$. For ordinary concrete, the amount of silica fume was usually less than $10 \%$. For high strength and durability concrete, it was necessary to increase the amount of silica fume to $10 \%$ in order to maintain a certain slump under the action of polycarboxylate [14]. The amount of silica fume in UHPC was usually less than $15 \%$ [15]. It was found that if the amount of silica fume was over $25 \%$, it would make UHPC very thick and reduce the flowability of UHPC. Meanwhile, the flowability of UHPC also decreased when the amount of slag exceeded $25 \%$ since the specific surface area of slag was smaller than that of cement; more free water was needed to achieve the same flowability. Therefore, silica fume and slag significantly affected the flowability of UHPC.

3.3. Strength. In the cementitious system of cement, silica fume, slag, and fly ash, UHPC was prepared by using M-PCE and Sika polycarboxylates, respectively. The strength of prepared UHPC is shown in Table 5. The quaternion orthogonal analysis of strength of UHPC is shown in Figures 6 and 7.

According to the UHPC strength test results in Table 5, the relationship between the 28-day strength $Y$ of UHPC with M-PCE and Sika used as polycarboxylate and the composition of cementing materials was established, as shown in the following equation:

$$
\begin{aligned}
Y_{(\mathrm{M}-\mathrm{PCE})}= & 1.074 X 1+1.164 X 2+2.192 X 3-3.006 X 4 \\
& +0.0044 X 1 X 2-0.01912 X 1 X 3+0.06038 X 1 X 4 \\
& -1.6665 X 2 X 3+0.1011 X 2 X 4+0.7579 X 3 X 4 \\
& +0.0034705 X 1 X 2 X 3-0.000729 X 1 X 2 X 4 \\
& -0.0008859 X 1 X 3 X 4-0.0067229 X 2 X 3 X 4 \\
& -0.000098075 X 1 X 2 X 3 X 4 \\
Y_{(\text {Sika })}= & 1.09 X 1+1.09 X 2+2.07 X 3-3.59 X 4 \\
& +0.0026 X 1 X 2-0.0138 X 1 X 3+0.072 X 1 X 4 \\
& -0.0808 X 2 X 3+0.2081 X 2 X 4+0.1396 X 3 X 4 \\
& +0.001438 X 1 X 2 X 3-0.003189 X 1 X 2 X 4 \\
& -0.0023989 X 1 X 3 X 4-0.008072 X 2 X 3 X 4 \\
& -0.00014719 X 1 X 2 X 3 X 4 .
\end{aligned}
$$

From formulas (6)-(7), it could be seen that either M-PCE or Sika was used, and the effect of silicate cement on the strength of UHPC ( $28 \mathrm{~d}$ ) was almost the same; that is, the coefficients on $X 1$ were almost the same. In addition, the coefficients of $X 4, X 1 X 3, X 2 X 3, X 1 X 2 X 3, X 1 X 2 X 3, X 1 X 2 X 4$, $X 1 X 3 X 4, X 2 X 3 X 4, X 1 X 2 X 3 X 4, X 1 X 2 X 3 X 4, X 1 X 2 X 3 X 4$, and $X 1 X 2 X 3 X 4$ were found to be negative, indicating that these incorporation methods had a negative synergistic effect on the strength of UHPC $(28 \mathrm{~d})$. Compared with the incorporation of silicate cement and silica fume, the incorporation of silicate cement and fly ash had a positive influence on the strength of UHPC $(28 \mathrm{~d})$.

It could be seen from Table 5 that there was little difference in the compressive strength of HUPC prepared with M-PCE and that prepared with Sika. The polyorganosiloxane group in M-PCE mother liquor could promote hydration. Although 
TABLE 3: Water reduction rate of polycarboxylate in mortar.

\begin{tabular}{lccccc}
\hline Polycarboxylate & Cement $(\mathrm{g})$ & Sand $(\mathrm{g})$ & Water $\left(M_{1}\right)(\mathrm{g})$ & Flowability & Water-reducing rate $(\%)$ \\
\hline M-PCE & 450 & 1350 & 128.6 & $180 \mathrm{~mm}, 183 \mathrm{~mm}$ & 37.3 \\
Sika & 450 & 1350 & 133.5 & $180 \mathrm{~mm}, 185 \mathrm{~mm}$ & 34.8
\end{tabular}

TABLE 4: Initial flowability of UHPC with different compositions (mm).

\begin{tabular}{|c|c|c|c|c|c|c|c|c|c|c|c|c|c|c|c|}
\hline \multirow{2}{*}{ Polycarboxylate } & \multicolumn{15}{|c|}{ Number } \\
\hline & $N 1$ & N2 & $N 3$ & N4 & N5 & N6 & N7 & N8 & N9 & N10 & $N 11$ & $N 12$ & N13 & N14 & N15 \\
\hline M-PCE & 165 & 153 & 125 & 192 & 170 & 172 & 195 & 193 & 235 & 170 & 165 & 146 & 155 & 178 & 102 \\
\hline Sika & 170 & 150 & 132 & 210 & 200 & 190 & 183 & 205 & 238 & 156 & 135 & 142 & 140 & 160 & 110 \\
\hline
\end{tabular}

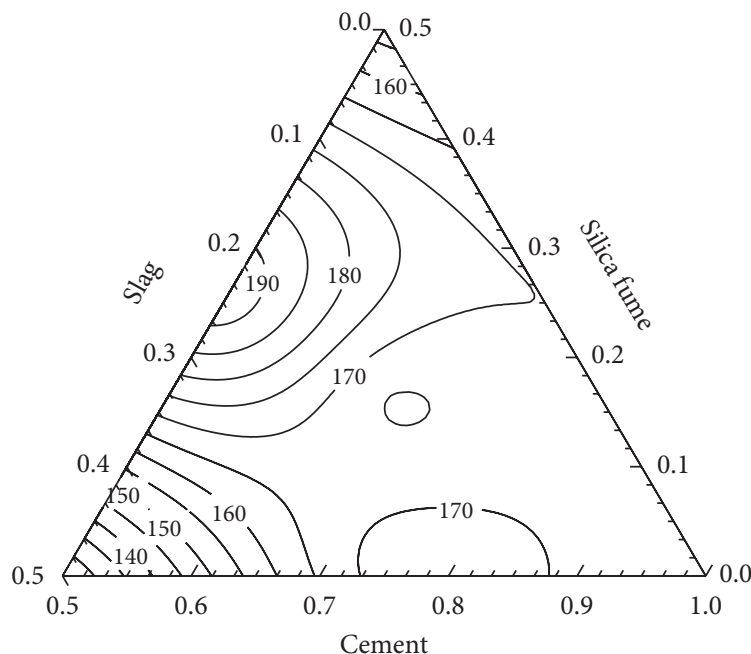

(a)

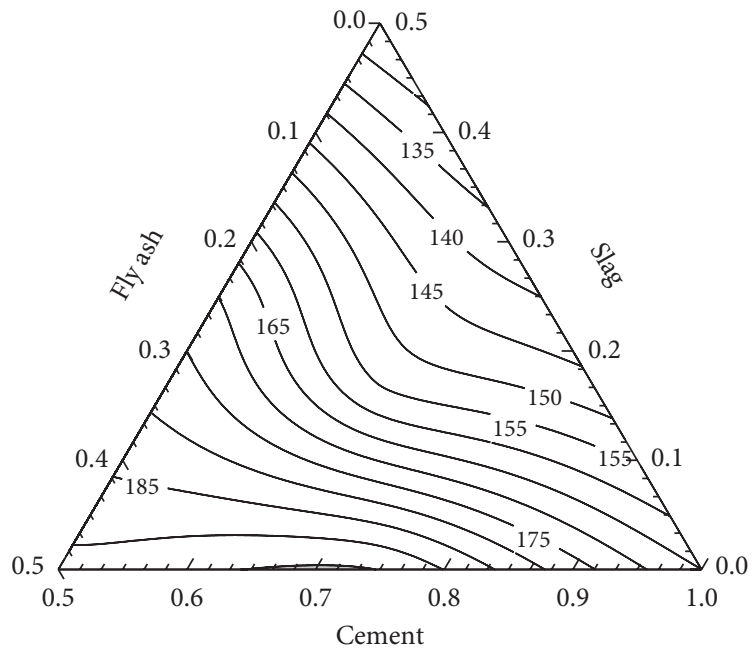

(c)

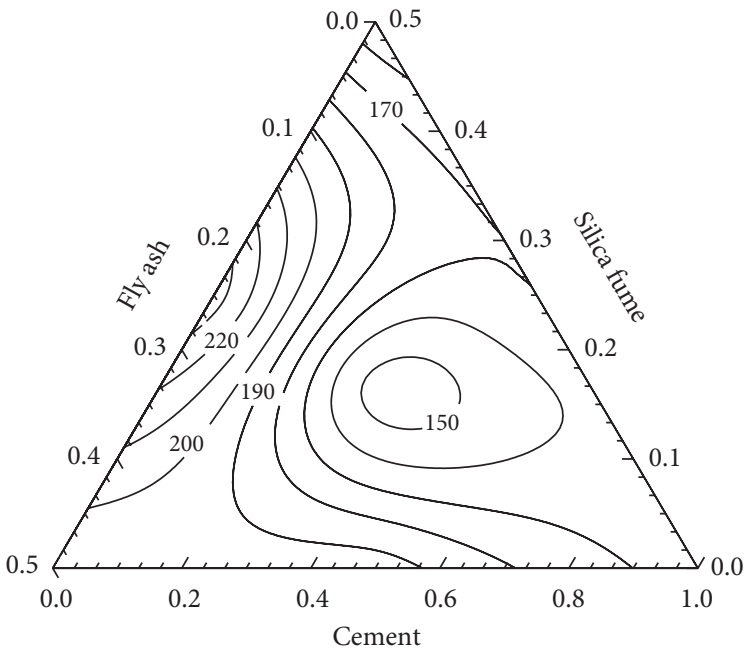

(b)

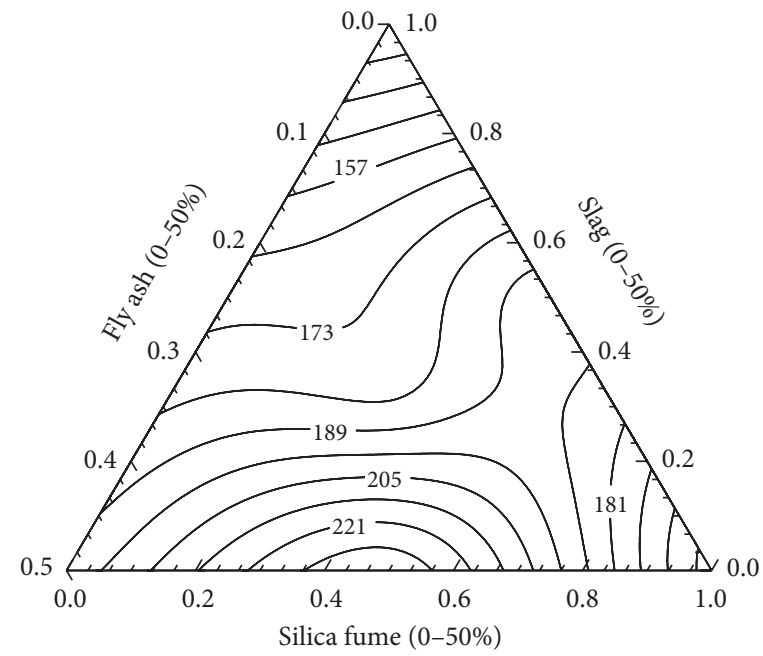

(d)

FIgURE 4: Flowability of UHPC with cement-silica fume-slag-fly ash binder (M-PCE). 


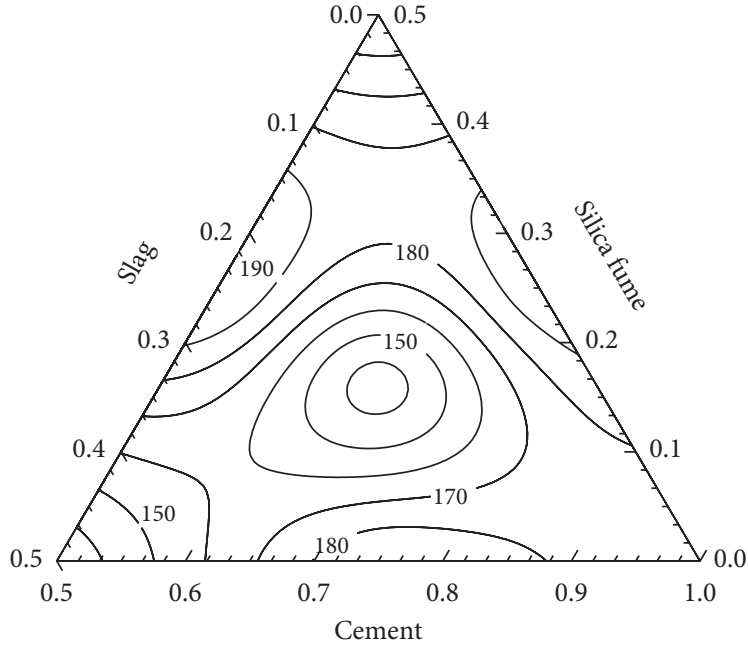

(a)

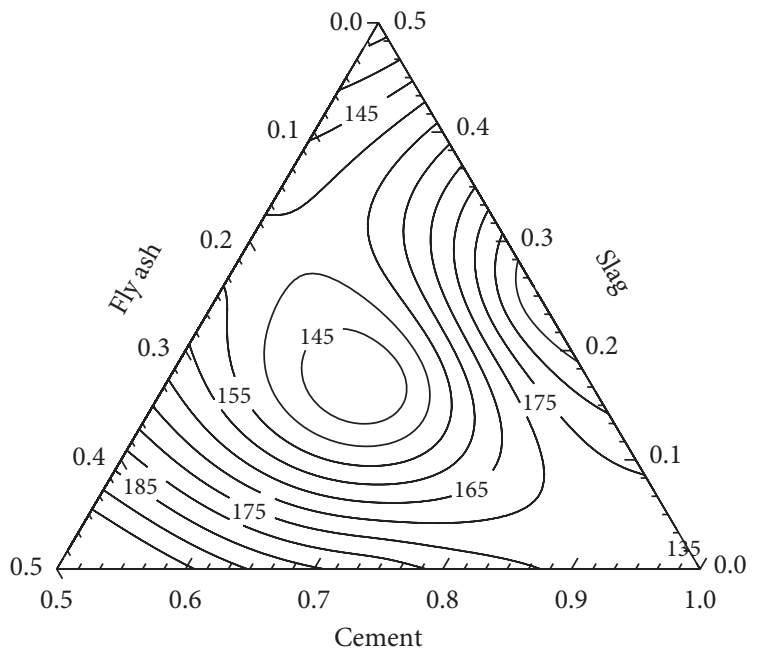

(c)

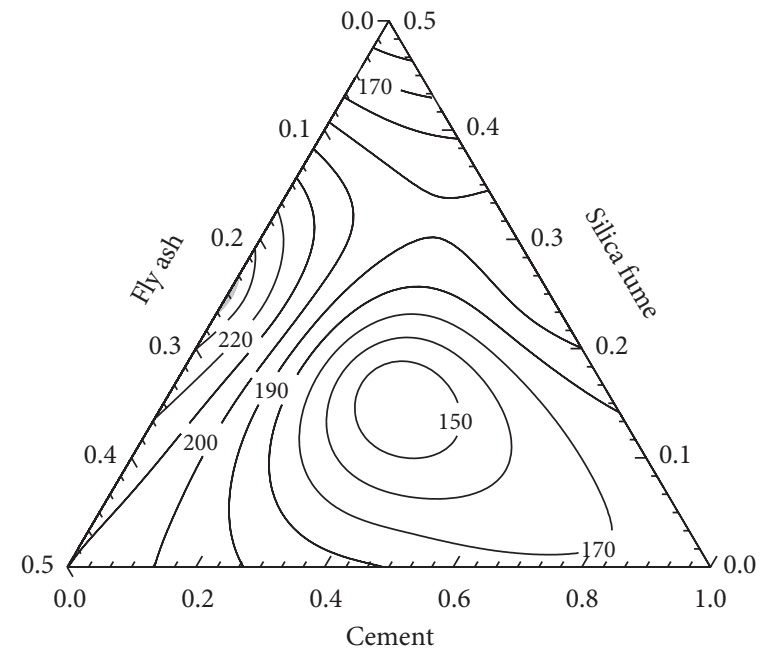

(b)

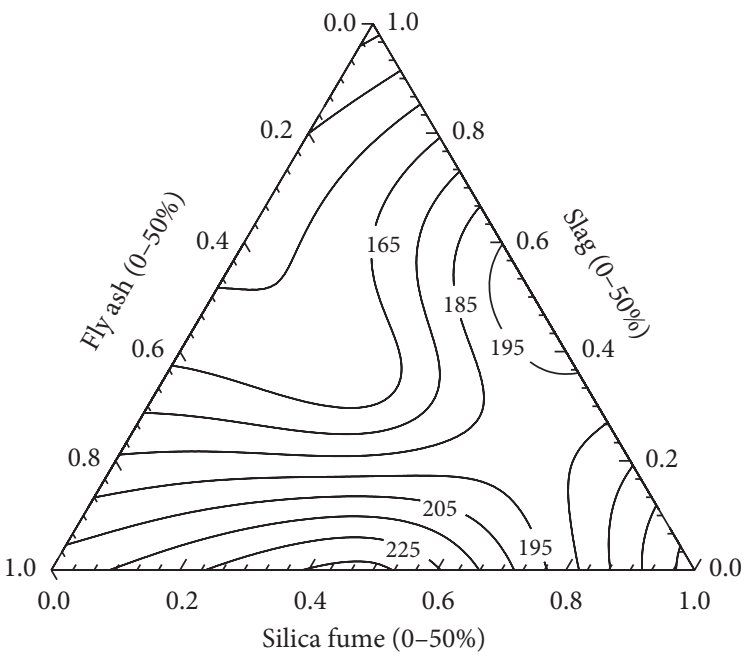

(d)

FIgURE 5: Flowability of UHPC with cement-silica fume-slag-fly ash binder (Sika).

TABle 5: Compressive strength of UHPC.

\begin{tabular}{|c|c|c|c|c|}
\hline \multirow{3}{*}{ Number } & \multicolumn{4}{|c|}{ Compressive strength (MPa) } \\
\hline & \multicolumn{2}{|c|}{ M-PCE } & \multicolumn{2}{|c|}{ Sika } \\
\hline & $3 \mathrm{~d}$ & $28 \mathrm{~d}$ & $3 \mathrm{~d}$ & $28 \mathrm{~d}$ \\
\hline$N 1$ & 71.6 & 107.4 & 74.8 & 108.8 \\
\hline$N 2$ & 74.5 & 100.9 & 82.1 & 115.4 \\
\hline$N 3$ & 70.0 & 115.5 & 83.7 & 123.3 \\
\hline N4 & 66.7 & 116.3 & 64.4 & 118.8 \\
\hline N5 & 71.2 & 101.4 & 80.4 & 113.7 \\
\hline N6 & 70.9 & 99.5 & 78.3 & 107.4 \\
\hline N7 & 64.7 & 118.6 & 84.8 & 126.9 \\
\hline N8 & 76.9 & 112.5 & 72.4 & 113.8 \\
\hline N9 & 81.0 & 117.4 & 86.9 & 115.6 \\
\hline$N 10$ & 79.3 & 104.6 & 81.5 & 101.5 \\
\hline N11 & 77.6 & 119.4 & 89.3 & 116.9 \\
\hline$N 12$ & 80.0 & 117.4 & 80.0 & 112.5 \\
\hline N13 & 85.8 & 108.5 & 83.8 & 106.2 \\
\hline N14 & 82.7 & 110.3 & 84.7 & 117.9 \\
\hline N15 & 86.4 & 118.7 & 83.6 & 109.1 \\
\hline
\end{tabular}




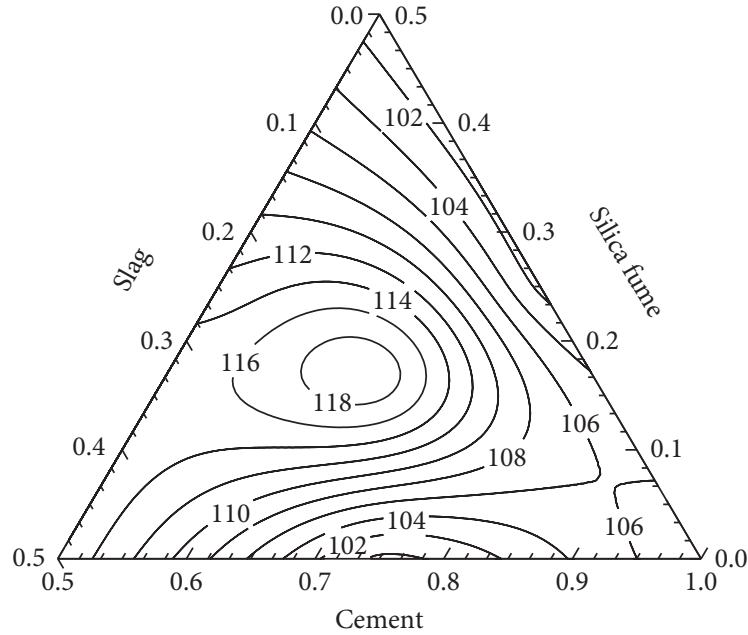

(a)

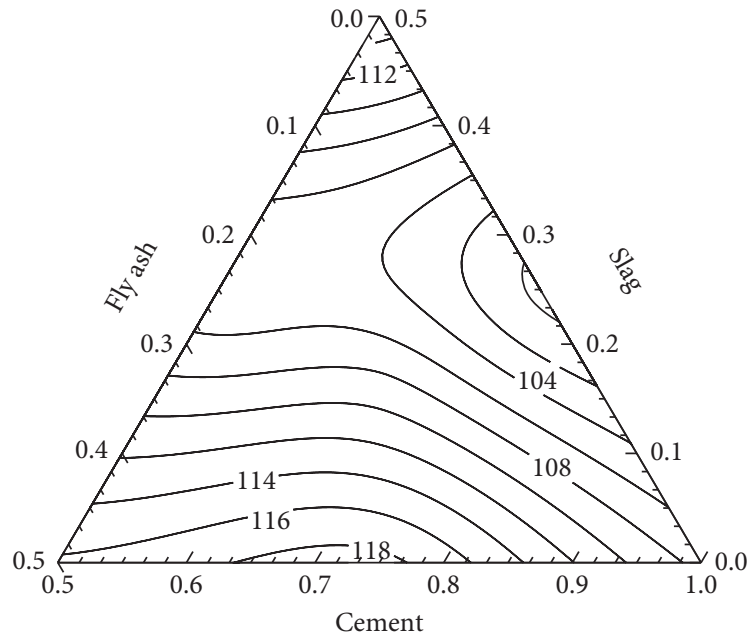

(c)

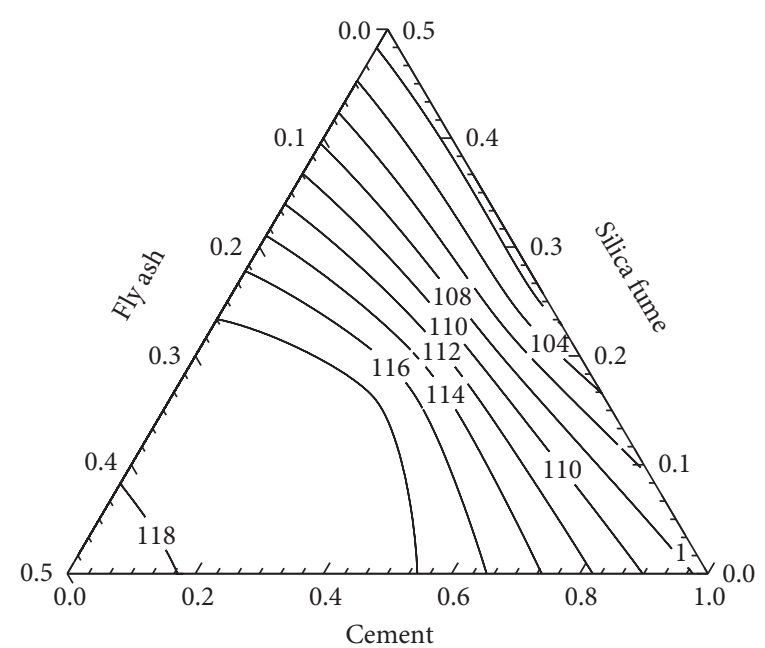

(b)

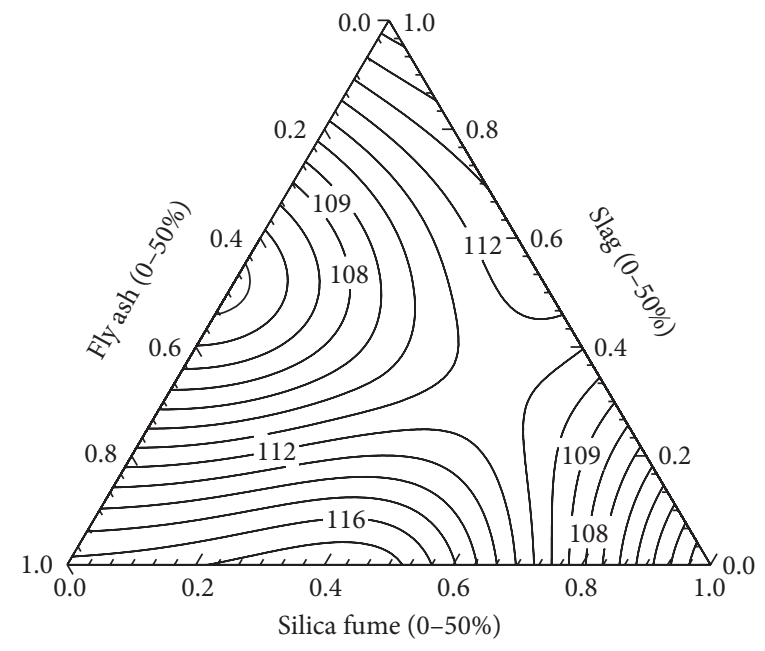

(d)

FIGURE 6: Compressive strength of UHPC (28d) with cementitious system of cement-silica fume-slag-fly ash (M-PCE).

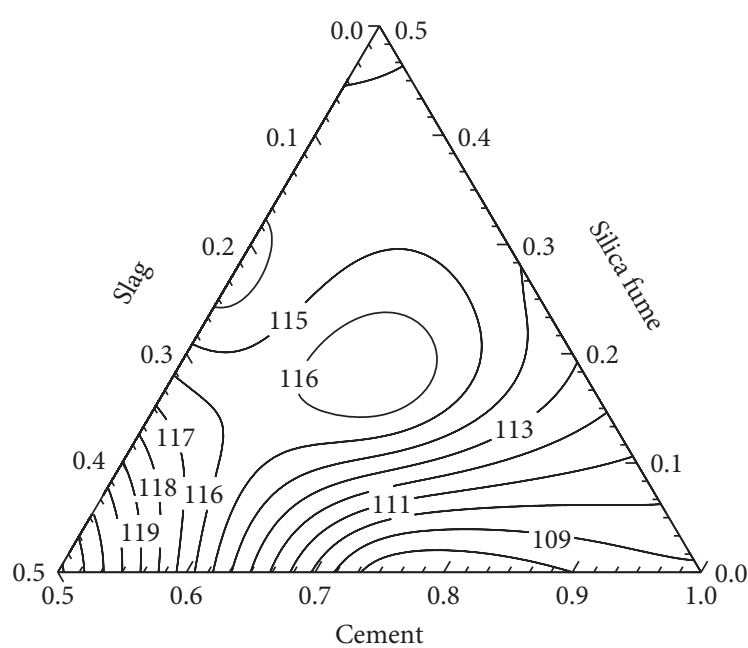

(a)

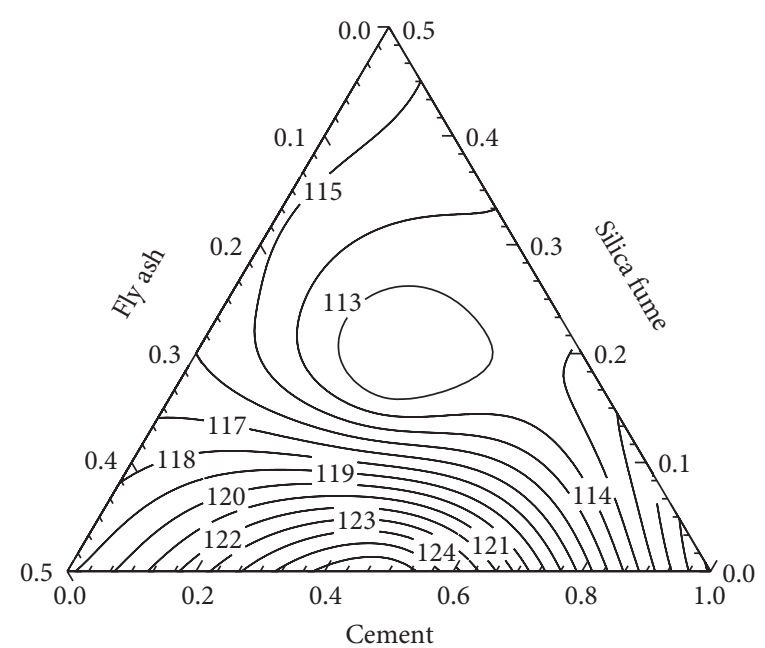

(b)

Figure 7: Continued. 


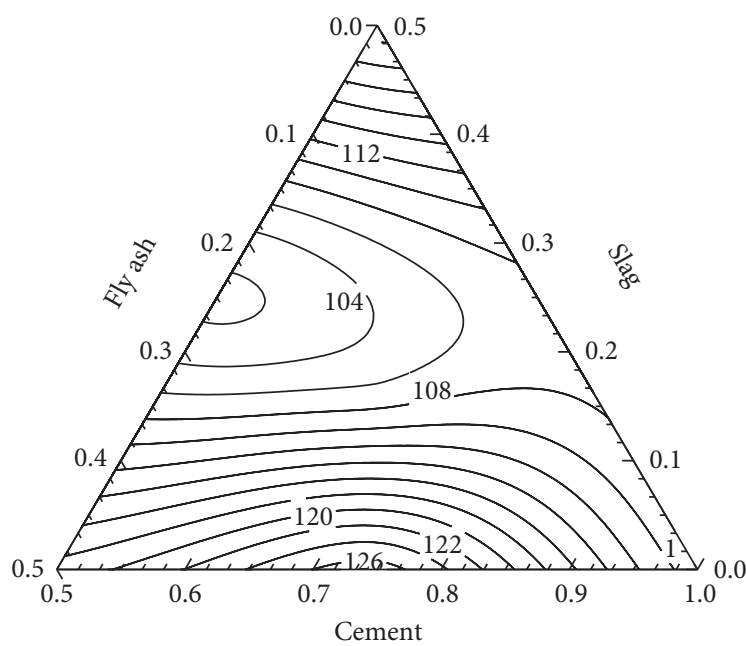

(c)

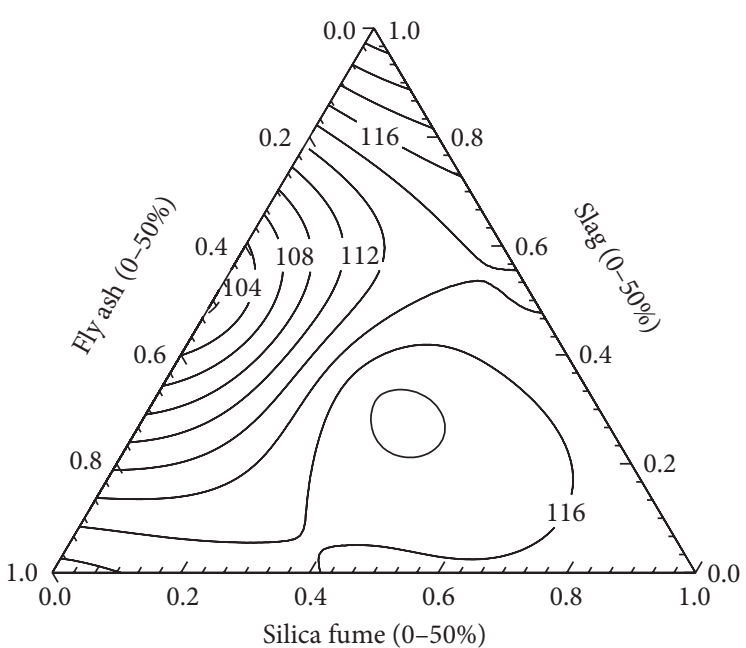

(d)

FIgURE 7: Compressive strength of UHPC ( $28 \mathrm{~d})$ with cementitious system of cement-silica fume-slag-fly ash (Sika).

Sika was relatively simple in the molecular structure, it could also be compatible with silicate cement and promote hydration due to its advanced compounding process. As the silica fume content increased, the early compressive strength of UHPC gradually increased; however when silica fume content exceeded 25\%, this trend slowed low. Due to the high pozzolanic activity and microaggregate effect of silica fume, silica fume could improve the compressive strength of UHPC. Amorphous $\mathrm{SiO}_{2}$ in silica fume reacts with calcium hydroxide produced by cement hydration to form hydrated calcium silicate $(\mathrm{C}-\mathrm{S}-\mathrm{H})$, which could improve the early strength of UHPC $[16,17]$. It could be seen from Table 5 that when the amount of silica fume was greater than $25 \%$, the compressive strength of UHPC (28 d) increased slightly with the increase in the amount of silica fume. In addition, it was found that the addition of slag reduced the compressive strength of UHPC (3d) but increased the strength of UHPC $(28 \mathrm{~h})$. This was because when silica fume and slag were mixed in a proper proportion, a suitable ratio of calcium to silicon (C/S) could be produced. Previous studies had shown that, in order to make concrete stronger, the optimal composition of cementing materials depends on the fineness of siliceous materials and the ratio of calcium to silicon [18]. When the ratio of calcium to silicon was $1.3: 1$, the strength of UHPC was greater than that of silica fume [19].

3.4. Dry Shrinkage. Under the cementation system of cement-silica fume-slag-fly ash, UHPC was prepared by using M-PCE and Sika polycarboxylate, respectively. The change in dry shrinkage of UHPC for $28 \mathrm{~d}$ is shown in Figures 8 and 9.

According to the 28-day dry shrinkage test results of UHPC in Figures 8 and 9, the relationship between the 28day dry shrinkage $Y$ of UHPC prepared with M-PCE and Sika as polycarboxylate and the composition of cementitious materials was established, as shown in the following equation:

$$
\begin{aligned}
& Y_{(\mathrm{M}-\mathrm{PCE})}=9 X 1+20 X 2+9 X 3-8 X 4-0.27 X 1 X 2 \\
& -0.06 X 1 X 3+0.17 X 1 X 4+0.72 X 2 X 3 \\
& +1.35 X 2 X 4+0.88 X 3 X 4-0.0123 X 1 X 2 X 3 \\
& -0.0228 X 1 X 2 X 4-0.014 X 1 X 3 X 4 \\
& -0.8226 X 2 X 3 X 4+0.015593 X 1 X 2 X 3 X 4 \text {, } \\
& Y_{(\mathrm{Sika})}=9 X 1+18 X 2+12 X 3-15 X 4-0.21 X 1 X 2 \\
& -0.01 X 1 X 3-0.29 X 1 X 4+0.43 X 2 X 3 \\
& +1.62 X 2 X 4+0.8896 \times 3 X 4-0.0071 X 1 X 2 X 3 \\
& -0.0287 X 1 X 2 X 4-0.0143 \times 1 X 3 X 4 \\
& -0.7467 X 2 X 3 X 4+0.013826 X 1 X 2 X 3 X 4 \text {. }
\end{aligned}
$$

From formulas (8)-(9), it could be seen that when M-PCE and Sika were used, silicate cement had the same effect on the drying shrinkage of UHPC $(28 \mathrm{~d})$; that is, the coefficients of $X 1$ were the same. In addition, the coefficients of $X 4, X 1 X 2, X 1 X 3, X 1 X 2 X 3, X 1 X 2 X 4$, and $X 1 X 3 X 4$ were all negative, indicating that the dry shrinkage of UHPC ( $28 \mathrm{~d})$ could be effectively reduced by only adding silicate cement and silica fume, slag, and fly ash.

As could be seen from Figures 8 and 9, the dry shrinkage value of UHPC prepared by M-PCE was slightly greater than that of UHPC prepared by Sika. Although the molecular structure of M-PCE contained a large number of waterreducing groups (alcohol groups), it was the M-PCE mother solution that was used in this experiment. In contrast, there were still water-reducing groups in Sika's molecular structure, which was more effective in reducing the surface tension of pore solution [20]. Therefore, the dry shrinkage of UHPC prepared by Sika would be smaller than that of UHPC prepared by M-PCE. 


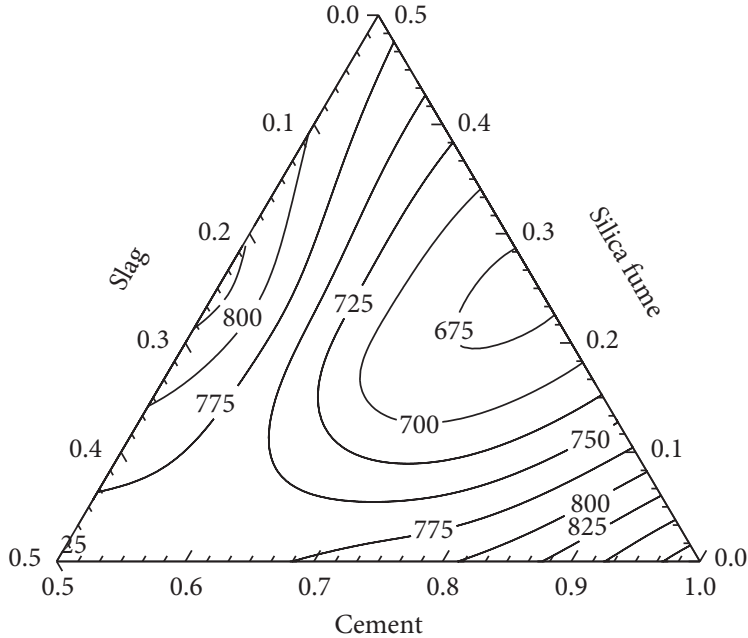

(a)

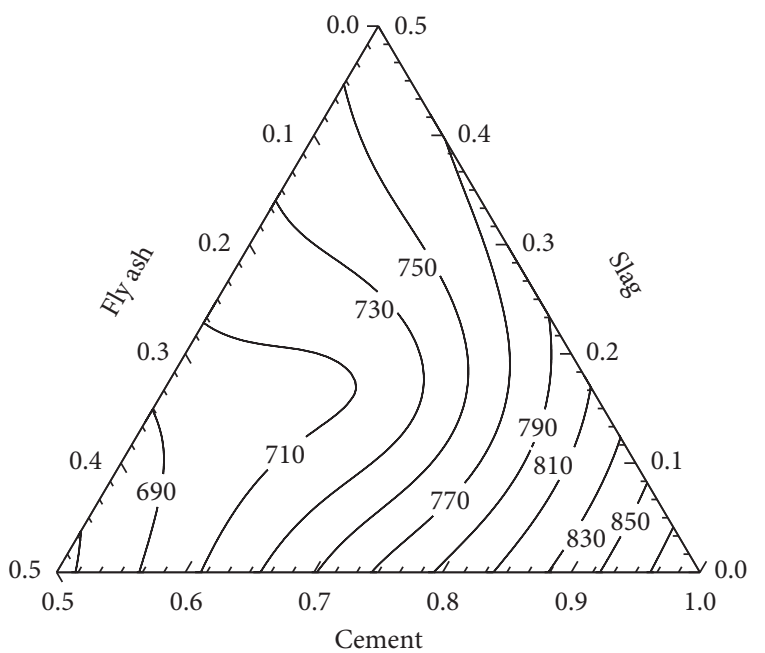

(c)

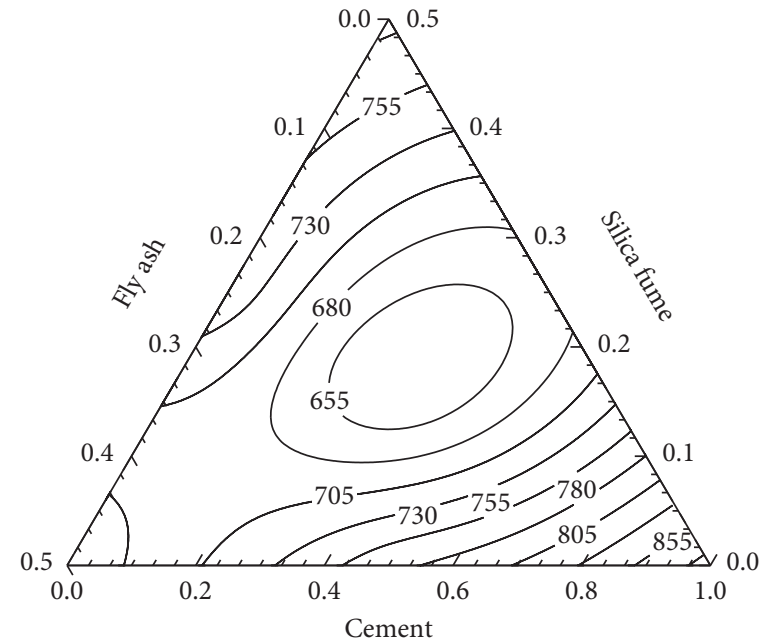

(b)

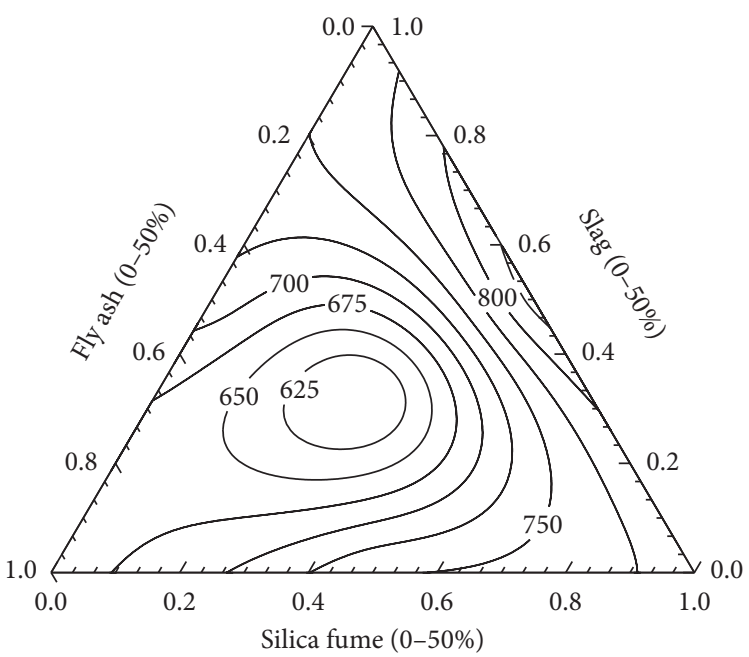

(d)

FIGURE 8: Dry shrinkage of UHPC (28d) with cementitious system of cement-silica fume-slag-fly ash (M-PCE).

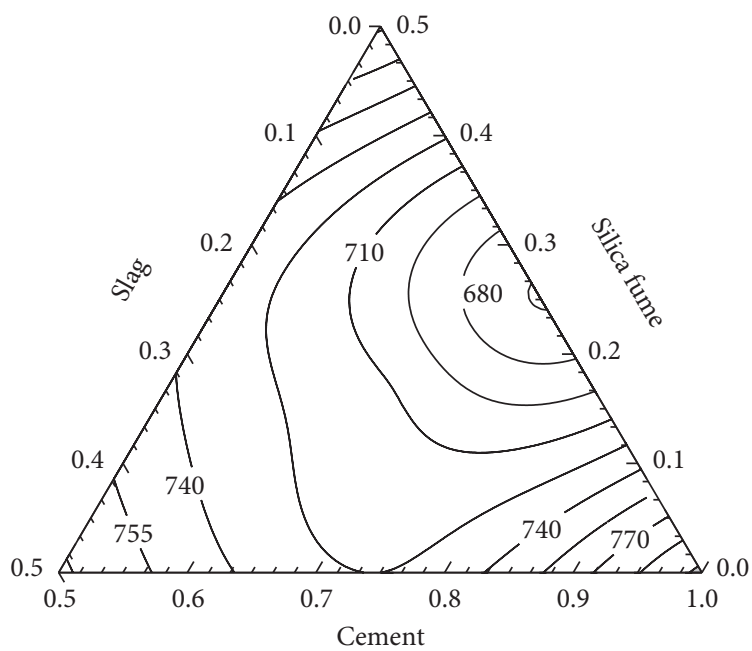

(a)

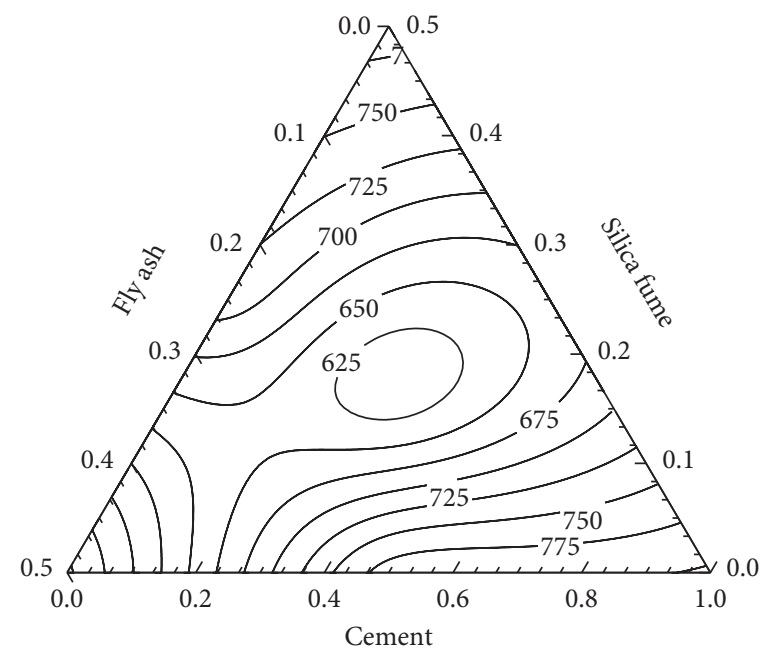

(b)

Figure 9: Continued. 


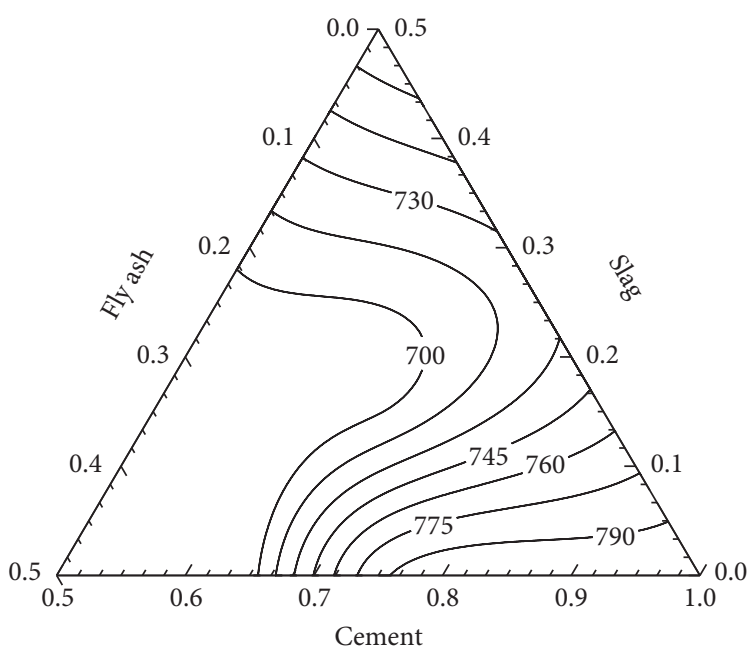

(c)

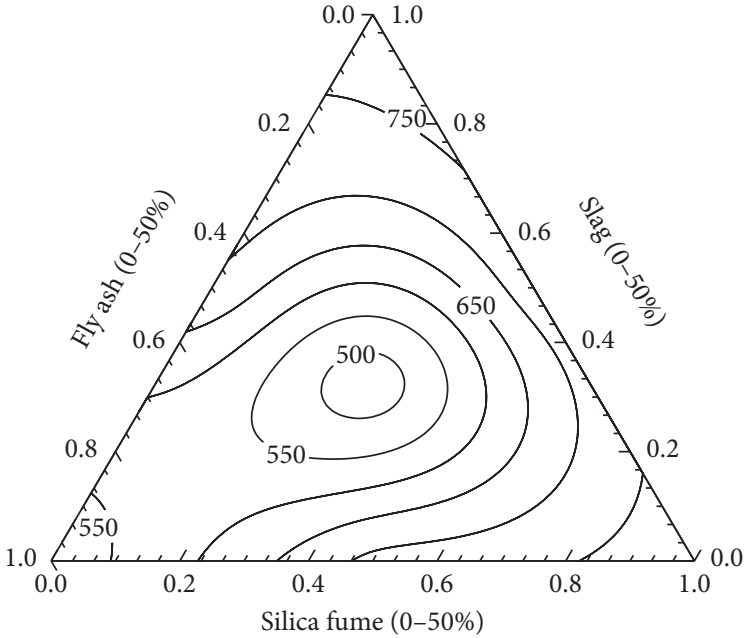

(d)

FIGURE 9: Dry shrinkage of UHPC (28d) with cementitious system of cement-silica fume-slag-fly ash (Sika).

The incorporation of fly ash would refine the pore structure of mortar, reduce the connectivity of pores, and increase the difficulty in water migration under drying conditions, which showed a positive effect on drying shrinkage; that is, drying shrinkage would be greatly reduced [21]. Therefore, it was found from Figures 8 and 9 that the dry shrinkage of UHPC became much larger when silica fume content was around $50 \%$. This was because the effect of silica fume on the drying shrinkage of UHPC was mainly due to the volcanic ash effect. Silica fume had high activity and could react with the hydration product $\mathrm{Ca}(\mathrm{OH})_{2}$ to form C-S-H gel, which, on the one hand, not only reduced the amount of flake crystal $\mathrm{Ca}(\mathrm{OH})_{2}$ and increased the amount of C-S-H in cement but also, on the other hand, refines the pore size and improves the pore structure. However, C-S-H gel itself had a porous structure and would contract under dry conditions, while $\mathrm{Ca}(\mathrm{OH})_{2}$ was a crystal structure, which generally would not contract. At the same time, part of $\mathrm{Ca}(\mathrm{OH})_{2}$ was distributed in the void of C-S-H gel, which had an inhibitory effect on its contraction [22]. The pozzolanite reaction consumes $\mathrm{Ca}(\mathrm{OH})_{2}$ in the cement, which eliminates the restriction effect of $\mathrm{Ca}(\mathrm{OH})_{2}$ on C-S-H gel shrinkage. Therefore, it could be deduced that the higher the reaction degree of volcanic ash, the greater the drying shrinkage value of the corresponding specimen. Theoretically, there was a positive correlation between the degree of ash reaction and the content of silica fume. Therefore, the incorporation of silica fume could enhance the dry shrinkage of UHPC.

3.5. Autogenous Shrinkage. Under the cementitious system of cement-silica fume-slag-fly ash, UHPC was prepared by using M-PCE and Sika, respectively, and the autogenous shrinkage changes in prepared UHPC are shown in Figures 10 and 11 .
According to the 3-day autogenous shrinkage test results of UHPC in Figures 10 and 11, the relation between 3-day autogenous shrinkage $Y$ of UHPC with either M-PCE or Sika and the composition of cementation material was established, as shown in the following equation:

$$
\begin{aligned}
Y_{(\mathrm{M}-\mathrm{PCE})}= & 9 X 1+3 X 2+48 X 3-61 X 4+0.38 X 1 X 2 \\
& -0.32 X 1 X 3+1.21 X 1 X 4-4 X 2 X 3 \\
& -2.69 X 2 X 4-0.07 X 3 X 4+0.06793 X 1 X 2 X 3 \\
& +0.05428 X 1 X 2 X 4+0.0098 X 1 X 3 X 4 \\
& +0.6089 X 2 X 3 X 4-0.010649 X 1 X 2 X 3 X 4,
\end{aligned}
$$

$$
\begin{aligned}
Y_{(\text {Sika) }}= & 9 X 1+11 X 2+27 X 3-78 X 4+0.81 X 1 X 2 \\
& -0.27 X 1 X 3+1.579 X 1 X 4-0.19 X 2 X 3 \\
& -0.1 X 2 X 4-2.01 X 3 X 4+0.0101 X 1 X 2 X 3 \\
& +0.0108 X 1 X 2 X 4+0.0435 X 1 X 3 X 4 \\
& +0.6575 X 2 X 3 X 4-0.01182 X 1 X 2 X 3 X 4 .
\end{aligned}
$$

From formulas (10)-(11), it could be seen that silicate cement had the same effect on the autogenous shrinkage of UHPC when either M-PCE or Sika was used; that is, the coefficients of $X 1$ were the same. In addition, the coefficients of $X 4, X 1 X 3, X 2 X 3, X 2 X 4, X 3 X 4$, and $X 1 X 2 X 3 X 4$ were all negative, indicating the autogenous shrinkage of UHPC could be effectively reduced by either adding fly ash, silicate cement and slag, silica fume and slag, silica fume and fly ash, or adding the four kinds of cementing materials. The other admixture measures all could increase the self-contraction of UHPC. As could be seen from Figures 10 and 11, the influence of M-PCE on UHPC self-shrinking was almost the same as that of Sika on UHPC. From the molecular perspective, their molecular 


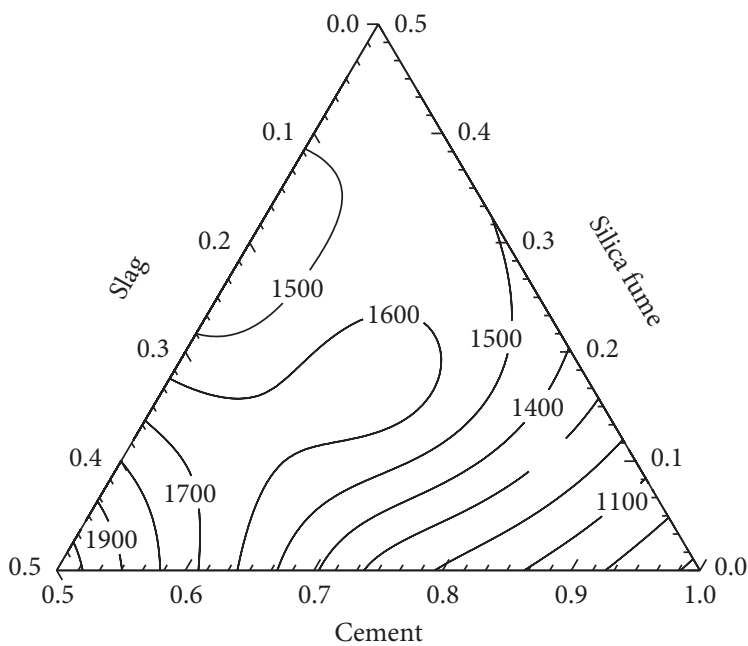

(a)

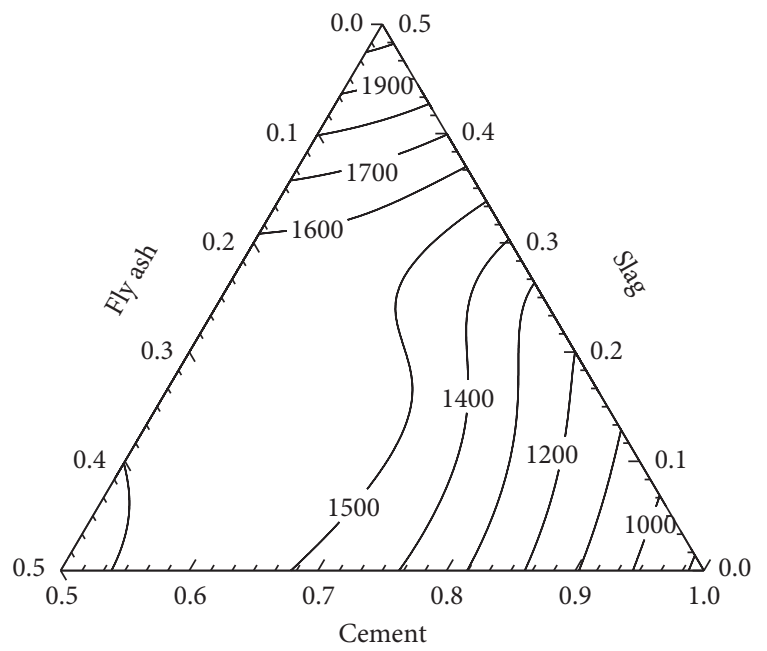

(c)

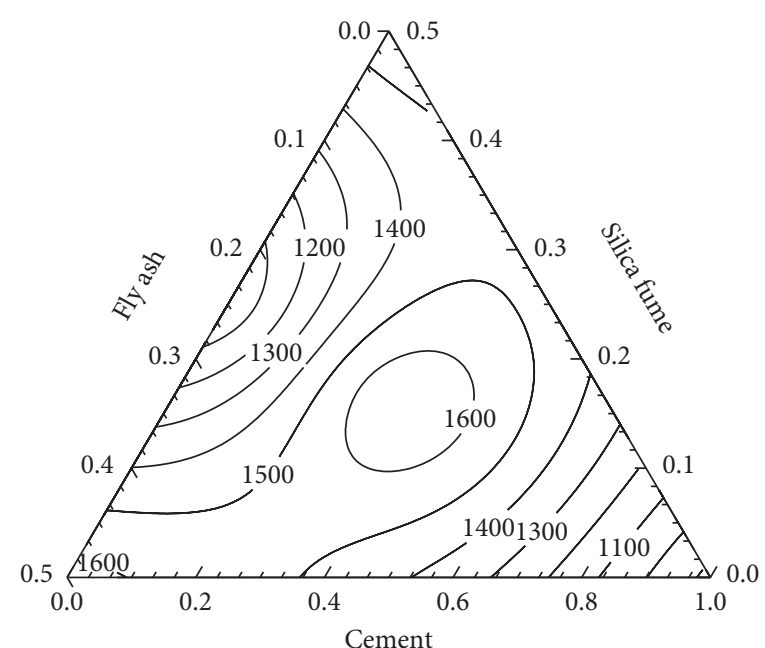

(b)

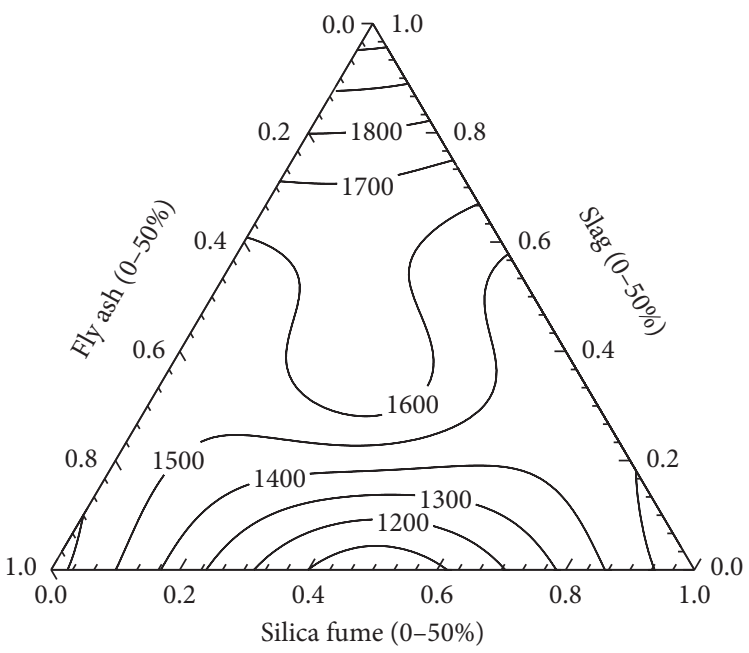

(d)

FIGURE 10: Autogenous shrinkage of UHPC (3d) with cementitious system of cement-silica fume-slag-fly ash (M-PCE).

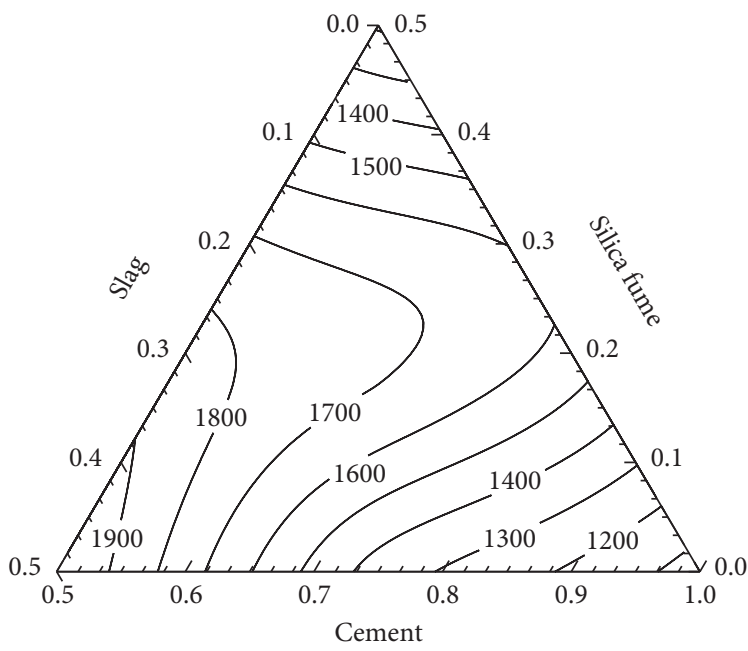

(a)

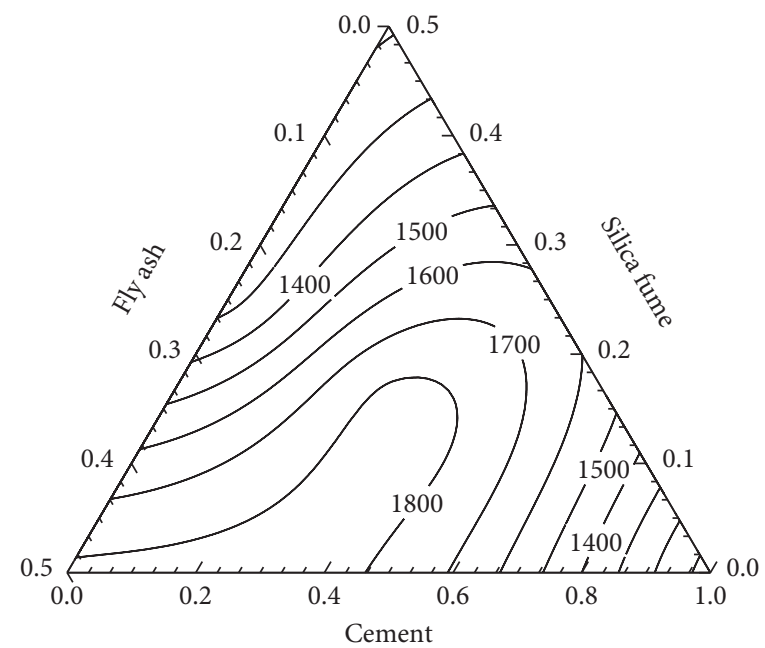

(b)

Figure 11: Continued. 


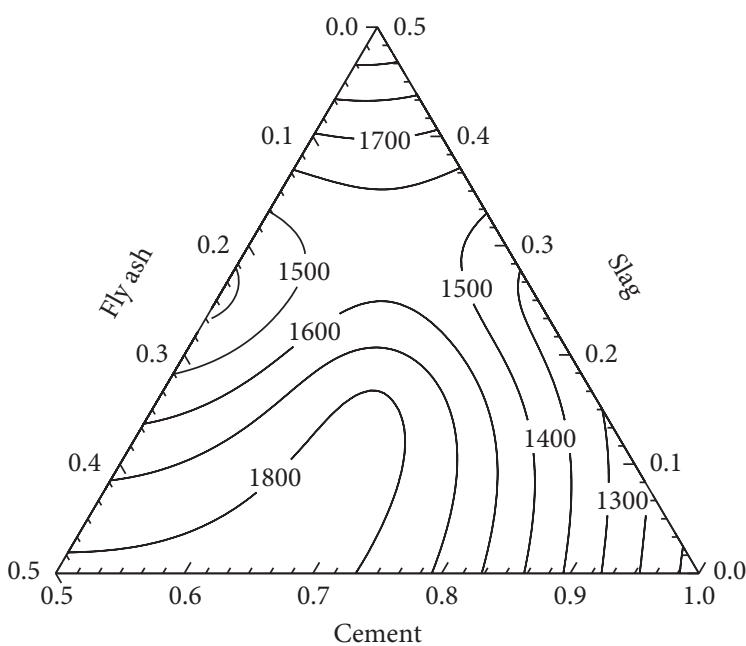

(c)

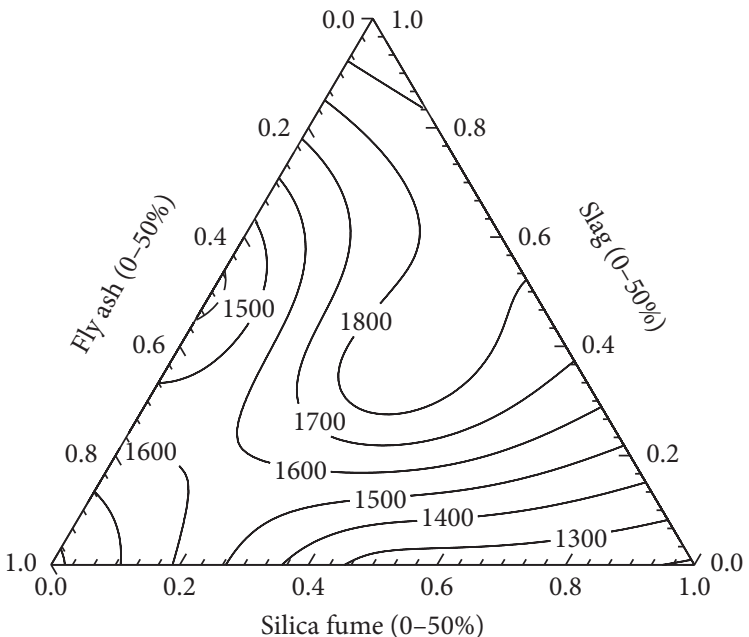

(d)

FIgURE 11: Autogenous shrinkage of UHPC (3d) with cement-silica fume-slag-fly ash binder (Sika).

structure contains a large number of polyethylene glycol reduction groups, which could effectively reduce the surface tension of pore solution. Therefore, the autogenous shrinkage value of UHPC prepared by pure silicate cement was small.

In addition, we found that adding silica fume alone would increase the autogenous shrinkage of UHPC, which was consistent with the results in [23]. The main reasons could be listed as follows: (1) silica fume fineness was large, and its unique filling effect could refine the pore structure of cement-based materials; (2) $\mathrm{Ca}(\mathrm{OH})_{2}$ generated in the early stage was not well grown and very small in particle size. After the addition of silica fume, it was easy to react quickly with silica fume to produce calcium silicate hydrate with low $\mathrm{C} / \mathrm{S}$ ratio, making the interface between the unhydrated cement particles and calcium silicate hydrate become more compact and uniform [24]; (3) when the content of silica fume was high, the excess silica fume could continue to react with the generated C-S$\mathrm{H}$ to produce the outer layer of calcium silicate hydrate with a lower $\mathrm{C} / \mathrm{S}$ ratio, making the structure of the cement-based materials doped with silica fume more dense [25]. Therefore, silica fume could reduce the porosity and average pore size of UHPC. Since the value of autogenous shrinkage was related to the capillary pressure of cementbased materials, the capillary pressure was mainly related to its diameter. The greater the silica fume content, the smaller the capillary diameter, the greater the capillary pressure, the greater the value of autogenous shrinkage of UHPC.

Because the chemical shrinkage induced by pozzolanic reaction of slag was greater than that induced by cement hydration, it was found that the effect of single dosage of slag on UHPC's autogenous shrinkage was great. Meanwhile, the activity and hydration degree of slag was greater than that of silicate cement, which greatly promoted the growth of capillary negative pressure and increased the action area $[26,27]$.

\section{Conclusions}

In this study, pectiniform polycarboxylate was synthesized at room temperature, and its applications in UHPC, including flowability, strength, drying shrinkage, and autogenous shrinkage, were investigated. The following conclusions could be obtained based on the above experimental results and discussion:

(1) The polysiloxane in molecular structure had better compatibility with silicate cement. When either M-PCE or Sika was used, the positive influence of silicate cement on the flowability of UHPC was the same. It is worth noting that the use of three or more cementitious materials had a negative synergistic effect on the flowability of UHPC although this effect was weak.

(2) There was little difference in compressive strength of HUPC prepared by M-PCE and Sika. The incorporation of cement with silica fume and that of cement with fly ash both had a positive effect on the 28-day strength of UHPC.

(3) The incorporation of fly ash could effectively reduce the drying shrinkage and autogenous shrinkage of UHPC. In terms of dry shrinkage, the dosage of silica fume and fly ash could effectively reduce the 28-day dry shrinkage of UHPC. Other incorporation methods would all increase the 28-day dry shrinkage of UHPC to varying degrees. From the perspective of autogenous shrinkage, the incorporation of silica fume and slag, that of silica fume and fly ash or that of all four cementing materials, could all effectively reduce the 3-day autogenous shrinkage of UHPC.

\section{Data Availability}

All the data used during the study are available from the corresponding author by request. 


\section{Conflicts of Interest}

The authors declare that there are no conflicts of interest.

\section{Authors' Contributions}

Shuncheng Xiang conceptualized the study, prepared methodology, investigated the study, performed data curation, did formal analysis, wrote the original draft, and revised the manuscript. Yingli Gao administrated the project, obtained funding acquisition, and supervised the study.

\section{Acknowledgments}

The authors gratefully acknowledge the financial support from the National Natural Science Foundation of China (General Program 51978080), Civil Aviation Administration of China (U1833127), Hunan Province Natural Science Foundation (2018JJ4016), Key Scientific Research Projects of Hunan Education Department (18A129), National Key R\&D Program of China (Grant number 2018YFB1600100), and Open Fund (Grant number kfj190503) of Key Laboratory of Special Environment Road Engineering of Hunan Province (Changsha University of Science \& Technology).

\section{References}

[1] P. J. Andersen, D. M. Roy, J. M. Gaidis, and WR Grace and Company, "The effects of adsorption of superplasticizers on the surface of cement," Cement and Concrete Research, vol. 17, no. 5, pp. 805-813, 1987.

[2] C.-Z. Li, N.-Q. Feng, Y.-D. Li, and R.-J. Chen, "Effects of polyethlene oxide chains on the performance of polycarboxylate-type water-reducers," Cement and Concrete Research, vol. 35, no. 5, pp. 867-873, 2005.

[3] B. He, Y. Gao, L. Qu, K. Duan, W. Zhou, and G. Pei, "Characteristics analysis of self-luminescent cement-based composite materials with self-cleaning effect," Journal of Cleaner Production, vol. 225, pp. 1169-1183, 2019.

[4] Y. Gao, L. Qu, B. He, K. Dai, Z. Fang, and R. Zhu, "Study on effectiveness of anti-icing and deicing performance of superhydrophobic asphalt concrete," Construction and Building Materials, vol. 191, pp. 270-280, 2018.

[5] C. J. Shi, "Recent development of PC superplasticizers," in Proceedings of the 2nd International Symposium on Mix Design, Performance and Use of SCC, pp. 16-25, Beijing, China, June 2009.

[6] K. R. Duan, Y. L. Gao, H. Yao et al., "Comparison of performances of early aged pre-vibrated cement-stabilized macadam formed by different compactions," Construction and Building Materials, vol. 239, 2020.

[7] P. C. Aitcin, "The durability characteristics of high performance con-crete: review," Cement and Concrete Composites, vol. 25, pp. 409-420, 2003.

[8] M. Jones, R. Dhir, and J. Gill, "Concrete surface treatment: effect of exposure temperature on chloride diffusion resistance," Cement and Concrete Research, vol. 25, no. 1, pp. 197-208, 1995.

[9] M. Levi, C. Ferro, D. Regazzoli, G. Dotelli, and A. Lo presti, "Comparative evaluation method of polymer surface treatments applied on high performance concrete,"
Journal of Materials Science, vol. 37, no. 22, pp. 4881-4888, 2002.

[10] J. L. Thompson, M. R. Silsbee, P. M. Gill, and B. E. Scheetz, "Characterization of silicate sealers on concrete," Cement and Concrete Research, vol. 27, no. 10, pp. 1561-1567, 1997.

[11] D. A. Kagi and K. B. Ren, "Reduction of water absorption in silicate treated concrete by post-treatment with cationic surfactants," Building and Environment, vol. 30, no. 2, pp. 237-243, 1995.

[12] R. P. Khatri, V. Sirivivatnanon, and W. Gross, "Effect of different supplementary cementitious materials on mechanical properties of high performance concrete," Cement and Concrete Research, vol. 25, no. 1, pp. 209-220, 1995.

[13] B. K. Ganesh and P. P. V. Surya, "Efficiency of silica fume in concrete," Cement and Concrete Research, vol. 25, no. 6, pp. 1273-1283, 1995.

[14] R. Duval and E. H. Kadri, "Influence of silica fume on the workability and the compressive strength of high-performance concretes," Cement and Concrete Research, vol. 28, no. 4, pp. 533-547, 1998.

[15] K. H. Khayat and P. C. Aitcin, "Silica fume: a uniquesupplementary cementitious material," in Mineral Admixturesin Cement and Concrete, S. N. Ghosh, Ed., pp. 227265,ABI Books Private Limited, New Delhi, India, 1993.

[16] M. Mazloom, A. A. Ramezanianpour, and J. J. Brooks, "Effect of silica fume on mechanical properties of high-strength concrete," Cement and Concrete Composites, vol. 26, no. 4, pp. 347-357, 2004.

[17] T. K. Erdem and Ö. Kirca, "Use of binary and ternary blends in high strength concrete," Construction and Building Materials, vol. 22, no. 7, pp. 1477-1483, 2008.

[18] A. Elahi, P. A. M. Basheer, S. V. Nanukuttan, and Q. U. Z. Khan, "Mechanical and durability properties of high performance concretes containing supplementary cementitious materials," Construction and Building Materials, vol. 24, no. 3, pp. 292-299, 2010.

[19] Y. Dang, N. Xie, A. Kessel, E. McVey, A. Pace, and X. Shi, "Accelerated laboratory evaluation of surface treatments for protecting concrete bridge decks from salt scaling," Construction and Building Materials, vol. 55, pp. 128-135, 2014.

[20] J. Zhang, L. Ding, F. Li, and J. Peng, "Recycled aggregates from construction and demolition wastes as alternative filling materials for highway subgrades in China," Journal of Cleaner Production, vol. 255, p. 120223, 2020.

[21] J. Zhang, F. Gu, and Y. Q. Zhang, "Use of building-related construction and demolition wastes in highway embankment: laboratory and field evaluations," Journal of Cleaner Production, vol. 230, pp. 1051-1060, 2019.

[22] H. Zhang, "The effect of curing conditions on compressive strength of ultra high strength concrete with high volume mineral admixtures," Building and Environment, vol. 42, pp. 2083-2089, 2007.

[23] S.-Y. Hong and F. P. Glasser, "Phase relations in the CaO$\mathrm{SiO}_{2}-\mathrm{H}_{2} \mathrm{O}$ system to $200^{\circ} \mathrm{C}$ at saturated steam pressure," Cement and Concrete Research, vol. 34, no. 9, pp. 1529-1534, 2004.

[24] M. H. Zhang, C. T. Tam, and M. P. Leow, "Effect of water-tocementitious materials ratio and silica fume on the autogenous shrinkage of concrete," Cement and Concrete Research, vol. 33, no. 10, pp. 1687-1694, 2003.

[25] H. Li, Z. Yi, and Y. Xie, "Progress of silane impregnating surface treatment technology of concrete structure," Materials Review, vol. 26, no. 3, pp. 120-125, 2012. 
[26] Z. D. Rong, W. Sun, H. J. Xiao, and W. Wang, "Effect of silica fume and fly ash on hydration and microstructure evolution of cement based composites at low water-binder ratios," Construction and Building Materials, vol. 51, pp. 446-450, 2014.

[27] M. H. F. Medeiros and P. Helene, "Surface treatment of reinforced concrete in marine environment: influence on chloride diffusion coefficient and capillary water absorption," Construction and Building Materials, vol. 23, no. 3, pp. 1476-1484, 2009. 